\section{Carcinoma In Situ Arising in a Gastric Hamartomatous Polyp in a Patient with Peutz-Jeghers Syndrome}

A 17-year-old girl with Peutz-Jeghers syndrome was referred to us in February 1988 with severe hypochromic anemia. Radiographic studies of the gastrointestinal tract revealed multiple gastric, duodenal, and jejunal polyps, and a single colonic polyp. Endoscopic examination of the upper gastrointestinal tract confirmed the presence of several gastric polyps, and the procedure was followed by an endoscopic polypectomy of the largest polyp $(20 \mathrm{~mm})$, which was diagnosed histopathologically as carcinoma in situ in a hamartomatous gastric polyp (Figure 1). Genetic studies confirmed the diagnosis. The family history did not show any similar cases.

The patient remained asymptomatic for approximately six months, but was then readmitted with acute upper gastrointestinal tract hemorrhage. Since an emergency upper gastrointestinal endoscopy failed to detect an active bleeding site, it was assumed that the patient was bleeding from the small intestinal polyps, and she underwent an exploratory laparotomy. During surgery, a jejunojejunal intussusception was identified, caused by a protruding polyp. The polyp was removed through a small longitudinal incision. A panendoscope was then passed through the incision into the jejunum, and five additional small intestinal polyps were identified and removed, with minimal enterotomies being carried out at the base of each polyp. The postoperative course was uneventful, and the patient was discharged and has remained in good health for the following seven years.

\section{R. Defagol, A. L. Higal , J. L. Campral', M. Paradelo',}

A. Uehara ${ }^{2}, M$. H. Torres Mazzucchi ${ }^{3}$, R. Videla ${ }^{l}$

'Gastroenterological Endoscopy Diagnosis and Research Center,

${ }^{2}$ Dept. of Surgery

${ }^{3}$ Dept. of Genetics, San Roque Hospital, Córdoba, Argentina

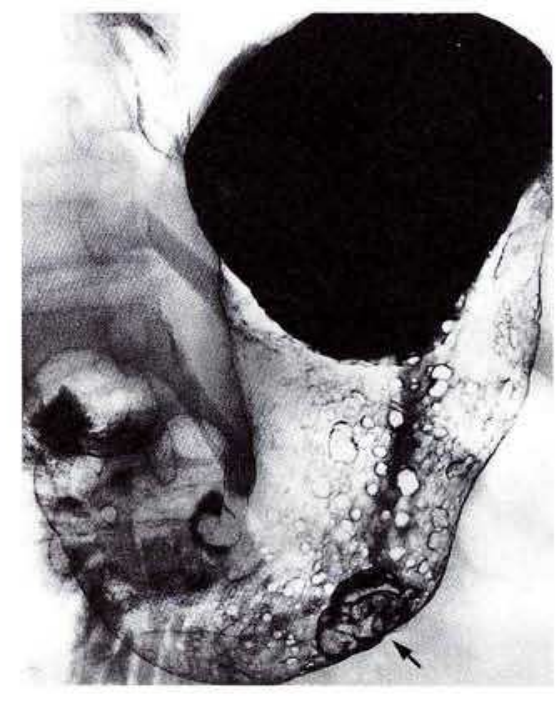

Figure 1: A double contrast view shows multiple polyps at the gastric body and the polyp cancer.

\section{References}

1. Giardello FM, Welsh SB, Hamilton SR, et al. Increased risk of cancer in the Peutz-Jeghers Syndrome. N Engl J Med 1987; 316: $1511-14$.

2. Reid JD. Intestinal carcinoma in the Peutz-Jeghers syndrome. J Am Med Assoc 1974; 7: 833-4.

3. Perzin KH, Bridge FM. Adenomatous and carcinomatous changes in hamartomatous polyps of the small intestine (PeutzJeghers syndrome): report of a case and review of literature. Cancer 1982; 49: 971-83.

4. Williams CB, Goldblatt M, Delaney PV. Top and tail endoscopy and follow-up in Peutz-Jeghers syndrome. Endoscopy 1982; 14: $82-4$.

5. Van Coevorden F, Mathus-Vliegen EM, Blummelkamp WH. Combined endoscopic and surgical treatment in Peutz-Jeghers syndrome. Surg Gynecol Obstet 1986; 162: 426-8.

Corresponding Author

A. L. Higa

Nicanor Carranza 4043

Cerro de las Rosas

5009 Córdoba, Argentina

Fax: +54-51-81-6628 